\title{
Modification of copper(I) - based activation solution with organic solvents and surfactants in the process of chemical copperplating
}

\author{
(C) Ludmila A. Brusnitsina, ${ }^{1,2 *+}$ Elena I. Stepanovskih ${ }^{1}$, and Tatiana A. Alexeeva ${ }^{1}$ \\ ${ }^{1}$ Physical Chemistry and Chemistry of Colloids Academic Department. \\ Ural Federal University Named after the First President of Russia B.N. Yeltsin. \\ Mira St., 19. Yekaterinburg, 620002. Russia.E-mail: brusnitsyna.l@yandex.ru \\ ${ }^{2}$ Ural Institute of the State Fire Service of the Ministry of Emergency Measures of Russia. \\ Mira St., 22. Yekaterinburg, 620062. Russia.
}

\begin{abstract}
*Supervising author; ${ }^{+}$Corresponding author
Keywords: copper(I) reduction, catalytic activity, organic solvents, surfactants, chemical copper plating, printed circuit.
\end{abstract}

In the processes of chemical and galvanic metallization of dielectric materials, in particular in the production of printed circuit boards, surface activation mainly uses compounds of precious metals and colloidal solutions characterized by limited stability during storage due to the coagulation process. To activate dielectric materials it is advisable to use true solutions based on monovalent copper compounds.

For continuous metallization of the dielectric, it is necessary to obtain a sufficiently large number of catalytic active centers on the surface. This can be achieved in two ways: to create a high concentration of $\mathrm{Cu}(\mathrm{I})$ in the activation solution or to increase the thickness of the activating layer.

The aim of this work is to modify the activating solution by introducing organic solvents and surfactants into its composition, contributing to an increase in the concentration of catalytically active centers on the dielectric surface.

In order to better distribute the activating solution on the dielectric surface and in the holes, as well as to increase the sorption of copper(I) by the adhesive layer, the modifying effect of organic solvents on the activating composition was studied. As such solvents, dimethylformamide (DMFA) and dimethyl sulfoxide (DMSO) used in the preparation of the surface of the adhesive layer were studied.

In the process of swelling, the solvent penetrates into the thickness of the adhesive layer. Due to this, the activator containing an organic solvent has the ability to be fixed on the surface not only due to the microroughness created in the etching process, but also able to penetrate deep into the swollen layer.

It is established that the maximum thickness of the swollen layer for $10 \%$ solution is reached by the time of swelling 30-40 minutes, for $20 \%$ - 20 minutes, for $50 \%$ - more than 45 minutes. By the time of swelling, equal to 5 minutes, for 10,20 and $50 \%$ solutions, the thickness of the swollen layer, respectively, is $1.00 ; 1.14 ; 1.55$ microns. It is shown that the presence of organic solvents in the activator increases the adhesion of the metal coating by an average of 1.3 times.

In order to better distribute the activator on the dielectric surface and in the holes, as well as to increase the adsorption of copper(I), it is advisable to introduce surfactants into the activator, which reduce the surface tension at the interface.

Introduction to the composition of the surfactant activating solution affect the adhesion of the metal to the dielectric. It was found that the introduction of surfactant into the activating solution leads to an increase in the concentration of copper on the dielectric surface.

Nonionic surfactant brand OP-10 in the activator provides a high concentration of catalytically active centers and get the highest adhesion of metal to the dielectric.

\section{References}

[1] M. Salkauskas, A. Vaskelis. Chemical metallization of plastics. Leningrad: Chemistry. 1985. 144p. (russian)

[2] L.A. Brusnitsina, E.I. Stepanovskih, T.A. Alekseeva, and V.I. Dvoinin. Photoreduction process modeling of copper(II) in the solid phase. Butlerov Communications. 2012. Vol.29. No.1. P.75-79. ROI: jbc-

02/12-29-1-75 
MODIFICATION OF COPPER(I) - BASED ACTIVATION SOLUTION WITH ORGANIC SOLVENTS...

[3] A.A. Abramzon. Surfactants. Properties and application. Leningrad: Chemistry. 1981. 304p. (russian)

[4] Surface-active substances. Reference book. ed. by A.A. Abramson and G.M. Gajewski. Leningrad: Chemistry. 1979. 376p. (russian)

[5] V.F. Nevolin. Chemistry and technology of synthetic detergents. Moscow: Food industry. 1964. $195 \mathrm{p}$. (russian)

[6] M.I. Bulatov, I.P. Kalinkin. Practical guide to photocolorimetric methods of analysis. Leningrad: Chemistry. 1972. 408p. (russian) 